\title{
DISTRIBUSI KARANG LUNAK DI PERAIRAN TELUK MANADO DENGAN PERBANDINGAN ANTARA KAWASAN NON REKLAMASI DAN REKLAMASI
}

\section{(Soft Coral Distribution In The Manado Bay Waters Between Non Reclamation And Reclamation Areas)}

\author{
Jerry M. Ch. Maramis ${ }^{1^{*}}$,Fontje G. Kaligis ${ }^{1}$ dan Janny D. Kusen ${ }^{1}$ \\ ${ }^{1}$ Program Studi IImu Kelautan, Fakultas Perikanan dan IImu Kelautan, Universitas Sam \\ Ratulangi, Manado \\ e-mail : jerymaramis@yahoo.com
}

Penelitian tentang distribusi karang lunak di Perairan Teluk Manado dengan perbandingan antara Kawasan Non Reklamasi dan Reklamasi telah dilakukan di Perairan Teluk Manado pada bulan Januari sampai dengan bulan Maret tahun 2013. Penelitian ini bertujuan untuk mengidentifikasi jenis-jenis karang lunak yang tersebar di perairan Teluk Manado khususnya di Pantai Kalasey serta mendeskripsikan kepadatan dan distribusi dari karang lunak.Pengambilan data dilakukan di perairan Malalayang pada daerah Non Reklamasi dan Reklamasi.Penelitian dimulai dengan melakukan survey awal di lokasi pengambilan data. Pada Setiap Lokasi penelitian mempunyai 3 stasiun pengamatan yaitu pada kedalaman 3 meter, 6 meter dan 9 meter, pengambilan data dilakukan dengan pencatatan bawah air menggunakan whotr plastic sheet dengan bantuan alat SCUBA dan kamera bawah air. Hasil analisis menunjukan bahwa kepadatan tertinggi terdapat pada daerah Reklamasi khususnya pada kedalaman 6 meter oleh Genus Xeniadengan nilai (K) $25.50 \mathrm{ind} / \mathrm{m}^{2}$ dan (KR) $95.39 \%$.Untuk pola penyebarannya pada dua lokasi penelitian adalah mengelompok.

Kata Kunci: Karang lunak, kepadatan, distribusi.

Study about soft coral distribution at Manado Bay, especially to compare their existence between Non-Reclamation and Reclamation areas were figured out from January to March, 2013. The aims of the study were to identified the soft corals species that distributed at Manado bay Waters, especially at Kalasey Beach, as well as to describe their density an distribution.Data gathering were worked out at Kalasey coastline zone to Non-reclamation and reclamation area respectively. The study were begin with preliminary survey at study site. At each study site has 3 observation station based on depth, those were $3 \mathrm{~m}, 6 \mathrm{~m}$, and $9 \mathrm{~m}$ deep. Data were noted by underwater white plastic sheet and underwater camera. Underwater work was supported by SCUBA diving.Analysis result has been shown that the highest density of soft coral were found at Reclamation area especially in $6 \mathrm{~m}$ deep by Genus Xenia within 25,50 ind. $/ \mathrm{m}^{2}$ of Density value and $95,39 \%$ of Relative Density. The distribution pattern at both study sites were grouped.

Keywords: Soft coral, density, distribution

\section{PENDAHULUAN}

Istilah oktokoral diidentikkan sebagai nama umum karang lunak yang memiliki 8 tentakel, tapi sebenarnya dari kelompok oktokoral dimasukkan 3 kelompok besar yaitu pena laut (sea pen), karang lunak (soft coral) dan gorgonia (sea fan). Ketiga kelompok ini secara sepintas mudah dibedakan, antara satu dengan lainnya, walaupun secara taksonomis sampai ke tingkat jenis mengalami banyak kesulitan (Colin dan Arneson, 1995 dalam Manuputty, 2008). 
Kelompok Oktokoral merupakan salah satu anggota Cnidaria yang juga berperan dalam pembentukan terumbu. Sama halnya dengan karang batu, bentuk tubuh anggota oktokoral berupa "polip" yaitu bentuk seperti bunga kecil, namun berbeda dengan karang batu dalam tekstur tubuhnya yang tidak memiliki kerangka yang keras tetapi berupa duriduri kecil dari senyawa kalsium karbonat, yang tertanam di dalam jaringan tubuhnya.

Studi tentang Distribusi Karang lunak di Perairan Sulawesi Utara, khususnya di Perairan Teluk Manado masih kurang,sehingga penelitian ini dianggap penting untuk mendapatkan informasi ilmiah.

\section{METODE PENELITIAN}

\section{a. Lokasi dan Waktu Penelitian}

Lokasi penelitian pada dua lokasi, yaitu kawasan non-Reklamasi di Pantai Malalayang dengan posisi geografis pada kisaran $01^{\circ} 27^{\prime} 39^{\prime \prime}$ 'LU-124.47'31'BT dan kawasan Reklamasi di perbatasan Kota Manado Kecamatan Malalayang Desa Kalasey dengan posisi geografis pada kisaran $\quad 01^{\circ} 27^{\prime} 42^{\prime \prime}$ LU-124047'0'BT Kabupaten Minahasa Provinsi Sulawesi Utara.

\section{b. Prosedur Kerja}

Pengambilan data pada 2 lokasi berbeda pada awalnya dilakukan survey pada lokasi penelitian yaitu Pantai Malalayang di depan penginapan tepi pantai merupakan daerah yang masih alamiah atau belum direklamasi (Lokasi A) dan daerah reklamasi dekat Tugu Boboca (lokasi B).

Pengambilan data menggunakan metode Transek Kuadran (Johan 2003). Pada tiap lokasi terdapat 3 stasiun pengamatan yaitu 3, 6 dan 9 meter, dimana masing-masing stasiun ditarik 3 transek dengan panjang transek 20 meter dengan jarak per transek pada tiap stasiun 5 meter dan masing-masing transek diletakkan 20 kuadran dengan ukuran 1x1 meter. Setelah kuadran diletakkan pada transek kemudian dilanjutkan dengan melakukan pengambilan data mengunakan kamera bawah air.

Proses identifikasi selanjutnya dilakukan dengan buku identifikasi Gosliner et al. (1996) dan Allen et al. (1994) dengan berdasarkan gambar atau foto yang sudah diambil, kemudian setiap jenis karang lunak yang ditemukan dicatat jumlahnya.

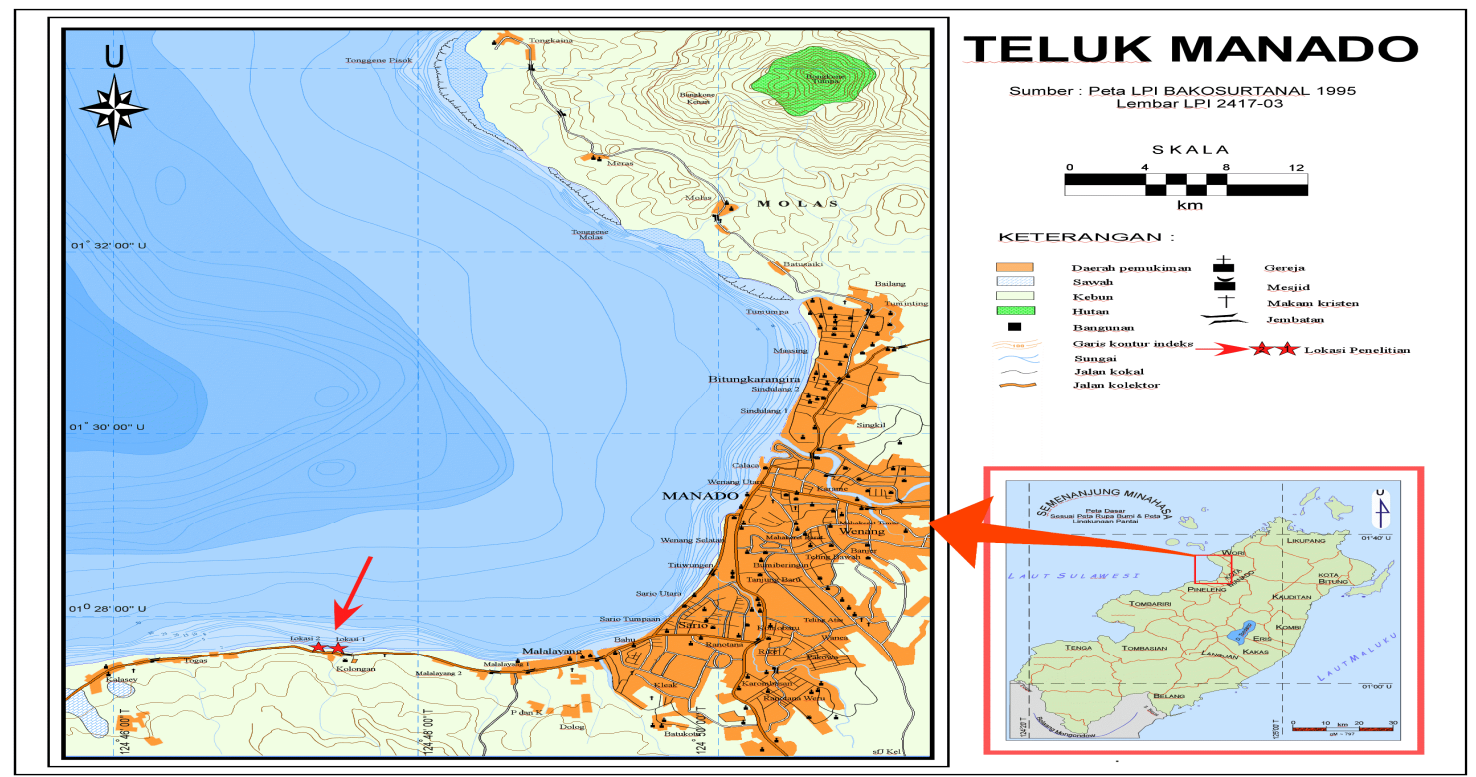

Gambar 1. Lokasi penelitian perairan Teluk Manado 


\section{c. Analisa Data}

\section{Kepadatan (K) Karang Lunak}

Kepadatan spesies karang lunak dianalisis dengan menggunakan rumus kepadatan (Krebs 1999):

$$
\mathrm{K}=\frac{n i}{A}
$$

Keterangan :

$K=$ Kepadatan suatu jenis (ind. $/ \mathrm{m}^{2}$ )

$n i \quad=$ Jumlah individu suatu jenis

$A \quad=$ Luas area $\left(\mathrm{m}^{2}\right)$

\section{Kepadatan Relatif(\%)}

Keterangan :

$$
\mathrm{KR}(\%)=\frac{n i}{\sum N} x 100
$$

$n i \quad=$ Jumlah individu suatu jenis

$N \quad=$ Total seluruh individu.

\section{Indeks Dispersi Morisita/ Distribusi}

$$
I_{\delta}=n\left(\frac{\sum x^{2}-\sum x}{\left(\sum x\right)^{2}-\sum x}\right)
$$

Dimana :

$I_{\bar{\delta}}=$ Distribusi spesies

$\mathrm{N}=$ Total jumlah kuadran seluruhnya

$\mathrm{X}=$ Jumlah individu padasetiap kuadran

Untuk menentukan signifikan losama dengan atau tidak sama dengan 1, maka digunakan kalkulasi sebagai berikut:

$$
x^{2}=I_{\delta}\left(\sum x-1\right)+n-\sum x
$$

Dimana jika :

$I_{\delta}=1$, distribusi spesies tersebut random/acak.

$l_{\circ}>1$, distribusi spesies tersebut berkelompok dan

$l_{\diamond}<1$, distribusi spesies tersebut seragam.

\section{HASIL DAN PEMBAHASAN}

Dari penelitian yang dilakukan ditemukan sebanyak 8 Genera Karang
Lunak pada lokasi Non Reklamasi dengan jumlah total sebanyak 1863 Individu dan 6 Genera Karang Lunak pada lokasi Reklamasi dengan jumlah total 475 Individu (ind). Hasil dari penelitian ini memperlihatkan bahwa daerah Non Reklamasi memiliki jumlah Genera dan jumlah individu paling banyak dibandingkan dengan daerah Reklamasi (Tabel 1).Dari keseluruhan jenis karang lunak yang ditemukan terlihat bahwa Xenia yang paling mendominasi pada daerah Non Reklamasi dan Reklamasi. Genus Xenia merupakan jenis karang lunak yang paling banyak ditemui di dua lokasi dimana dengan total 1794 ind, kemudian diikuti oleh Klyxum sp (140 ind), Nephthea (122 ind), Lobophytum (95 ind), Sinularia (90 ind), Sarcophyton (77 Ind), Lemnalia (11 Ind), Paralemnalia (9 Ind).

Tabel 1. Jumlah individu Karang Lunak pada Dua Lokasi Berbeda

\begin{tabular}{|c|c|c|c|c|}
\hline \multirow{2}{*}{ No } & \multirow{2}{*}{ Genus } & \multicolumn{2}{|c|}{ Lokasi } & Total \\
\cline { 3 - 4 } & $\begin{array}{c}\text { Non } \\
\text { Reklamas } \\
\mathrm{i}\end{array}$ & $\begin{array}{c}\text { Reklamas } \\
\mathrm{i}\end{array}$ & $\mathrm{u}$ \\
\hline 1 & Nephthea & 113 & 9 & 122 \\
\hline 2 & Klyxum sp & 95 & 45 & 140 \\
\hline 3 & Sinularia & 56 & 34 & 90 \\
\hline 4 & Lobophytum & 27 & 68 & 95 \\
\hline 5 & Paralemnalia & 9 & - & 9 \\
\hline 6 & Sarcophyton & 18 & 59 & 77 \\
\hline 7 & Xenia & 1534 & 260 & 1794 \\
\hline 8 & Lemnalia & 11 & - & 11 \\
\hline \multicolumn{2}{|c|}{ Jumlah } & $\mathbf{1 8 6 3}$ Ind & $\mathbf{4 7 5}$ Ind & $\mathbf{2 3 3 8}$ \\
\hline
\end{tabular}

\section{Kepadatan}

Dari hasil yang didapat ternyata daerah Non Reklamasi lebih padat dibandingkan dengan daerah Reklamasi, khususnya pada kedalaman 6 meter di daerah Non Reklamasi kepadatan tertinggi oleh genus Xenia dengan nilai (K) 25.50 ind $/ \mathrm{m}^{2}$ dan (KR) $95.39 \%$ dimana substrat serta intensitas cahaya yang masuk dan kadar salinitas pada kedalaman ini sangat mendukung 
keberadaan genus ini. Substrat yang cocok pada genus ini adalah patahan karang keras yang pada umumnya mati serta bebatuan dan pasir.Xenia dapat di temukan pada rataan terumbu sampai pada kedalaman 10 meter (Manuputty 1996).

Sedangkan kepadatan tertinggi di daerah Reklamasi terdapat pada kedalaman 3 meter oleh genus Xenia dengan nilai (K) $3.05 \mathrm{ind} / \mathrm{m}^{2}$ dan (KR) $68.54 \%$, substrat menjadi salah satu faktor yang membuat genus ini padat. Faktor lingkungan yang sangat penting mempengaruhi penyebaran dan kepadatan karang lunak adalah interaksi faktor biologi-fisik. Hewan ini sering menyebar pada kedalaman dibawah surut terendah menghindari proses pengeringan (Bayer 1956 dalam Akbar 2013).

Karang lunak tersebut selalu melimpah pada karang mati dan batuan dasar.Substrat kelihatannya merupakan faktor yang sangat penting untuk menentukan penyebaran karang lunak ini (Arafat 2009). Pada perairan dangkal, aksi gelombang juga merupakan faktor pembatas untuk karang lunak berkolonisasi, sedangkan pada perairan dalam, ketersediaan cahaya merupakan faktor pembatas karang lunak untuk berkolonisasi (Tursch dan Tursch 1982 ).

\section{Pola Sebaran/ Distribusi}

Krebs (1999) menyatakan ada tiga tipe pola distribusi yaitu acak, teratur dan mengelompok.Hasil analisis pola distribusi pada karang lunak di dua lokasi penelitian berbeda di tampilkan pada Tabel 7.Umumnya pola distribusi karang lunak pada daerah Non Reklamasi dan daerah Reklamasi adalah mengelompok $\left(I_{\delta}>1\right)$. Ketersediaan substrat dan makanan di kedua lokasi penelitian ini yang kemungkinan menjadi penyebab karang lunak ini mengelompok. Faktor lingkungan yang sangat penting mempengaruhi penyebaran dan kelimpahan karang lunak adalah interaksi faktor biologi dan fisik serta tipe substrat. Hewan ini sering
Tabel 2. Indeks Penyebaran pada Dua Lokasi Penelitian

\begin{tabular}{|c|c|c|}
\hline \multicolumn{3}{|c|}{ Distribusi } \\
\hline $\begin{array}{c}\text { Kedalaman } 3 \\
\text { Meter }\end{array}$ & Non Reklamasi & Reklamasi \\
\hline Transek A & $\begin{array}{c}1.57 \\
\text { (Mengelompok) }\end{array}$ & $\begin{array}{c}2.80 \\
\text { (Mengelompok) }\end{array}$ \\
\hline Transek B & $\begin{array}{c}1.81 \\
\text { (Mengelompok) }\end{array}$ & $\begin{array}{c}1.74 \\
\text { (Mengelompok) }\end{array}$ \\
\hline Transek C & $\begin{array}{c}1.46 \\
\text { (Mengelompok) }\end{array}$ & $\begin{array}{c}3.79 \\
\text { (Mengelompok) }\end{array}$ \\
\hline \multicolumn{3}{|c|}{ Distribusi } \\
\hline $\begin{array}{c}\text { Kedalaman } 6 \\
\text { Meter }\end{array}$ & Non Reklamasi & Reklamasi \\
\hline Transek A & $\begin{array}{c}2.13 \\
\text { (Mengelompok) }\end{array}$ & $\begin{array}{c}1.75 \\
\text { (Mengelompok) }\end{array}$ \\
\hline Transek B & $\begin{array}{c}1.53 \\
\text { (Mengelompok) }\end{array}$ & $\begin{array}{c}2.26 \\
\text { (Mengelompok) }\end{array}$ \\
\hline Transek C & $\begin{array}{c}2.02 \\
\text { (Mengelompok) }\end{array}$ & $\begin{array}{c}1.82 \\
\text { (Mengelompok) }\end{array}$ \\
\hline \multicolumn{3}{|c|}{ Distribusi } \\
\hline $\begin{array}{c}\text { Kedalaman } 9 \\
\text { Meter }\end{array}$ & Non Reklamasi & Reklamasi \\
\hline Transek A & $\begin{array}{c}1.96 \\
\text { (Mengelompok) }\end{array}$ & $\begin{array}{c}1.58 \\
\text { (Mengelompok) }\end{array}$ \\
\hline Transek B & $\begin{array}{c}1.51 \\
\text { (Mengelompok) }\end{array}$ & $\begin{array}{c}3.98 \\
\text { (Mengelompok) }\end{array}$ \\
\hline Transek C & $\begin{array}{c}1.17 \\
\text { (Mengelompok) }\end{array}$ & $\begin{array}{c}3.33 \\
\text { (Mengelompok) }\end{array}$ \\
\hline
\end{tabular}

menyebar pada kedalaman di bawah surut terendah menghindari proses pengeringan (Bayer 1956 dalam Arafat 2009).

\section{Parameter Lingkungan}

Pengukuran parameter lingkungan pada Dua lokasi berbeda memliki suhu dengan kisaran 29-30 ${ }^{0} \mathrm{C}$ dengan kecerahan berkisar antara 10-15 meter.Untuk salinitas perairan dengan kisaran 30-35\%.Dari data yang diperoleh terlihat bahwa masing-masing lokasi tidak memiliki perbedaan yang mencolok antara lokasi satu dengan lokasi lainnya, dikarenakan daerah penelitian terletak ada satu perairan yang lokasinya tidak terlalu jauh.

Kisaran suhu yang terdapat pada daerah penelitian ini dapat digolongkan dalam kondisi sangat baik, karena dalam kisaran 28-30 ${ }^{\circ} \mathrm{C}$.Dari salinitas yang didapati di daerah penelitian dapat dikatakan bagus.Nybakken (1992) 
menyatakan bahwa perkembangan terumbu yang paling optimal terjadi di perairan yang rata-rata suhu tahunannya 23-25 ${ }^{\circ} \mathrm{C}$.Sedangkan intensitas cahaya berkurang sampai $15-20 \%$ dari intensitas permukaan sedangkan untuk kisaran salinitas yang baik bagi pertumbuhan terumbu karang adalah $30-35 \%$.

\section{KESIMPULAN}

Kesimpulan yang dapat diambil dari penelitian ini yaitu:

1. Terdapat 8 genera Karang Lunak pada lokasi Non Reklamasi dengan jumlah total sebanyak 1863 Individu dan 6 Genera Karang Lunak pada lokasi Reklamasi dengan jumlah total 475 Individu (ind).

2. Kepadatan tertinggi pada Daerah Non Reklamasi diperlihatkan oleh genus Xenia dengan nilai (K) $25.50 \mathrm{ind} / \mathrm{m}^{2}$ dan pada Daerah Reklamasi oleh Xenia dengan nilai $3.05 \mathrm{ind} / \mathrm{m}^{2}$.

3. Pola distribusi karang lunak yang ada pada dua lokasi penelitian berbeda ialah mengelompok.

\section{DAFTAR PUSTAKA}

Akbar, M. 2013. Kaitan Kondisi Oseanografi Dengan Kepadatan Dan Keanekaragaman Karang Lunak Di Pulau Laelae, Pulau Bonebatang Dan Pulau Badi. Jurusan IImu Kelautan, Fakultas IImu Kelautan Dan Perikanan. Universitas Hasanuddin, Makasar

Allen, G.R. Steene, R. 1994. Indo-Pacific Coral Reef Field Guide. Singapore.

Arafat, D. 2009. Pertumbuhan Karang Lunak (Octocorallia:Alcyonacea) Lobophytum strictum, Sinularia dura dan Perkembangan Gonad Sinularia dura Hasil Fragmentasi Buatan Di Pulau Pramuka,
Kepulauan Seribu, Jakarta. Institut Pertanian Bogor, Bogor.

Gosliner, M, T. Behrens, W, D. Wiliams, C, G 1996. Coral reef animals of The Indo-Pacific : Animal life from Africa to Hawaii Exclusive of the vertebrates. Sea Challengers. Monterey, California. 32-50.

Johan, O. 2003.Metode Survei Terumbu Karang Indonesia. Disampaikan pada Training Course: Karakteristik Biologi Karang. Yayasan TERANGI, 8 halaman.

Krebs,C.J. 1999. Ecological Methodology.Harper Collins Publishers. Columbia.

Manuputty, A. E. W. 1996. Pengenalan Beberapa Karang Lunak (Octocorallia, Alcyonacea), Di Lapangan.Oseana, Volume XXI, Nomor 4.1-11.

Manuputty, A. E. W. 2008. Beberapa Aspek Ekologi Oktokoral. Oseana, Volume XXXIII, Nomor 2, :33-42

Nybakken, J. W. 1992. Biologi Laut: Suatu Pendekatan Ekologis.. Penerbit. PT. Gramedia Pustaka Utama, Jakarta. 